\title{
Epidemiological, Characteristics and Outcomes of Road Traffic Accident Among Patients in Emergency Units
}

\author{
Ahmed Abdulhasan Hussein Alogaili*, Abeer Gatea and Wisam Abdulridha Khullof* \\ MBCHB, High Diploma in Emergency Medicine, Iraqi Ministry of Health. Baghdad, Iraq \\ *Corresponding author: Ahmed Abdulhasan Hussein Alogaili and Wisam Abdulridha Khullof, MBCHB, High Diploma in \\ Emergency Medicine, Iraqi Ministry of Health. Baghdad, Iraq
}

\section{ARTICLE INFO \\ Received: 㓞 August 21, 2021 \\ Published: 櫘 September 03, 2021}

Citation: Ahmed Abdulhasan Hussein Alogaili, Abeer Gatea, Wisam Abdulridha Khullof. Epidemiological, Characteristics and Outcomes of Road Traffic Accident Among Patients in Emergency Units. Biomed J Sci \& Tech Res 38(4)-2021. BJSTR. MS.ID.006173.

Keywords: Road Traffic Accident; Outcomes; Fractures; Emergency units; Iraq; Provinces

Abbreviations: AIS: Abbreviated Injury Severity Scale; MAIS: Maximal AIS ;ISS: Injury Severity Score; ICD: International Classification of Diseases

\begin{abstract}
Traffic accidents constitute about $85 \%$ of deaths, especially in developing countries. Traffic accidents have become a source of anxiety and terror among everyone, with an impact on human, technical and environmental factors. This study aimed to identify the epidemiological, characteristics and outcomes of Road Traffic accident among patients in emergency unit during the study period. A retrospective cross sectional study was conducted among 198471 patients with road traffic injuries were registered at 15 provinces on Iraq. The data reported to the present study were collected between January 2020 and December 2020. Data onto patients were recorded including cause and location of injury, frequency and type of injury (frequency of soft tissue injuries and bone fractures), as well as age and gender distribution. Males comprised $70.2 \%$ of the total fatalities, while females accounted for $29.8 \%$. The age group of $15-44$ years was the most vulnerable $(54.71 \%)$ of the total cases followed by the age group 5-14 years $(20.8 \%)$ and $\geq 45$ years $(16.6 \%)$. Majority of victims were unemployed $(61.2 \%)$ and (65\%) were married.

Car accident constituted the large victim group of road traffic accident fatalities and injuries (32.9\%), followed by motorcycle $(25.7 \%)$. The official statistics revealed of the threat to minibus (16.1\%) and lorry (15.3\%). out of total number of 78201 cases $(39.4 \%)$ that sustained head injury, Skull fractures were found in 44361 (22.4\%) cases of head injury. Among other injuries, most commonly injured abdominal organ was $(16.6 \%)$ followed by the upper extremity (16.2\%). Conclusion in short, it has been shown in this study that male gender, young ages, and involvement of cars and drivers and pedestrians pose a higher risk, mortality, and morbidity. Our results may be useful for forensic pathologists and clinicians and for mechanical engineers who investigate new safety devices for vehicle occupants.
\end{abstract}

\section{Introduction}

Traffic accidents are one of the most unfortunate reasons that claim dozens of lives every day around the world, in addition to the occurrence of many injuries and serious damage to the means of transportation, despite the increase in awareness campaigns in global traffic weeks, and throughout the year as well, and the causes of traffic accidents are many [1-3]. There is a continuous increase in the number of victims due to traffic accidents; In 2016, the number of deaths resulting from car accidents reached 1.35 million people around the world, but this percentage is considered constant with the increase in population numbers around the world, and the increase in the number of cars, and this indicates the efforts made to maintain the safety of road users, which led to a lack of It gets worse, knowing that one of the sustainable development goals, which is to reduce the death rates from accidents by $50 \%$ 
by 2020, has not yet been achieved [4-6]. Life and death; the care of the injured is a very delicate matter; If it is done wrong, it may lead to the death of the injured, or aggravate his injury, and this can be avoided by registering in specialized training programs in ambulance, and caring for the injured from accidents [7-8].

The continent of Africa is the highest in recording death rates from accidents, and the ages of deaths resulting from traffic accidents range between young people and children from 5 to 29 years old, while males cause road accidents at a higher rate than females, accounting for $73 \%$ of deaths that result from accidents [9-10]. Therefore, the RTA occurred among the youngest under the age of 25 years [11]. Traffic accidents leave a lot of damage, whether economic, social, or human, and these accidents have several consequences and many costs, and these costs, for example: treatment of the injured, the length of their care, and the loss of the production process due to injury [12-13]. In addition to the loss of welfare and material losses service to the injured, rescue operations, police work, investigations into the cause of the accident, and in addition to these losses, the costs and damages resulting from accidents are also borne by the families of the victims and injured [14]. While the costs of accidents in developing countries are estimated at 65 billion dollars annually; that is, it exceeds the amounts provided annually for development aid, and it must be said that all efforts made for maintain the safety of drivers while driving on the roads have not achieved the required results [15].

Adolescents, especially those ages between 16 to 19 years, should be educated and given sufficient experience and the necessary skill to take responsibility for driving and to keep them safe on the roads because of its great role in avoiding accidents [16]. Statistics indicate that the aforementioned age group is the most likely to die as a result of car accidents, and they cause four times more horrific accidents than the age group between 25 to 69 years [17]. Technology plays an important role in preventing car accidents, reducing the risk of injury, and maintaining the safety of both drivers and pedestrians, such as: sending warning signals before a collision occurs, enabling the driver to avoid an accident, facilitating the detection of blind spots on the vehicle, and improving brake systems [18]. Therefore, the driver must choose a car with high safety specifications, and advanced technology to improve safety while driving and, asking about the vehicle's specifications before purchasing it [19]. This study aimed to identify the epidemiological, characteristics and outcomes of Road Traffic accident among patients in emergency unit during the study period.

\section{Methodology}

A retrospective cross sectional study was conducted among 198471 patients with road traffic injuries were registered on fifteen provinces in Iraq. The data reported on the present study were collected between January 2020 and December 2020. Data were collected including medical history, patient symptoms, clinical signs and the radiological findings. Data onto patients were recorded including cause and location of injury, frequency and type of injury (frequency of soft tissue injuries and bone fractures), as well as age and gender distribution. Duration of recovery and associated complication was also recorded. Road traffic injuries were classified into [20], soft-tissue injuries, fractures and injuries of organs. Soft-tissue injuries were classified into abrasion, contusion and laceration. Fractures were classified into; skull (fissure and depressed fractures) and long bones. The Glasgow Coma Scale was used to assess the severity of brain injury. A conservative or operative intervention done for all the cases was also recorded. Traffic accidents are classified according to the E code of the International Classification of Diseases (ICD).

By definition, this category includes all accidents involving at least one vehicle for any kind. The definition used in the present study embraces also pedestrians injured in an accident not involving another person or vehicle, e.g. an injury caused by slipping or stumbling [21]. Objective measures of injury severity -the injury severity score (ISS) and the 1990 revision of the abbreviated injury scale (AIS-90) was determined. The AIS is a scale for categorizing injury type and severity. The body is divided into six regions (i.e., head or neck, face, chest, abdomen, extremities, and external) in which injuries are graded from 1 (minor) to 6 (clinically untreatable). The maximal AIS (MAIS), which is the highest single AIS code in a patient with multiple injuries, was determined. The ISS, which is useful for assessing the severity of multiple injuries, is the sum of the squares of the highest AIS coded in each of much three most severely injured body regions [22]. Statistical analyses performed included descriptive analysis, chi square test, Fisher's exact test, and Mann-Whitney's U test. This was followed by logistic regression analyses to determine the impact on the main causes of craniofacial injuries. The SPSS Version 16.0 (SPSS Inc., Chicago, IL) and Epi Info ${ }^{\mathrm{TM}}$ Version 3.5 were used for statistical analyses.

\section{Results}

Out of 198471 of RTA patients, half of them $54.7 \%$ occurred in the age group 15 to 44 years old and $20.8 \%$ in the age 4 to 14 years old. Male cases $70.2 \%$ were more than $29.8 \%$ female cases. $61.2 \%$ were unemployed and $65 \%$ were married. Car constitutes the large victim group of road traffic accident fatalities and injuries (32.9\%), followed by motorcycle (25.7\%), $16.1 \%$ by minibus and $15.3 \%$ by lorry (Table1). In Table 2 shows that the highest frequency $22.4 \%$ of them had fractures ;followed by $17.4 \%$ had spinal injuries, $15.9 \%$ had burnt abdominal injuries, $10.7 \%$ and $10.2 \%$ had TBJ and burnt chest injuries respectively. In Figure 1 shows the highest frequency (39.4\%) 78201/198471 had injury in head and neck rejoin followed by (16.6\%) 33025/198471 in abdominal 
rejoin and (16.2\%) 32121/198471 in upper extremity rejoin. The studied cases were divided into six groups according to abbreviated injury severity scale (AIS), the highest number of patients scored AIS 3(32.8\%) and the least number (6.5\%) scored AIS 6 (Table $3)$. According to outcome of studied cases involved in road traffic accidents,32.8\% discharged after recovery , 5.6\% absconded, $22.2 \%$ transferred to other hospital or unit and , 39.4\% died (Table 4). Out of 78219 victims, 24158cases (30.9\%) died instantly and 54061 (69.1) \% died after a period of hospitalization (Table 5). Out of the hospitalized victims, $21.8 \%$ died in the first $24 \mathrm{~h}, 33.8 \%$ died in a period of 1-10 days, $18.4 \%$ died in 11-20 days, and $26 \%$ died in more than 21 days (Table 6).

Table 1: Characteristics of RTA among patients in emergency units.

\begin{tabular}{|c|c|c|}
\hline Variables & Frequency (198471) & Percent \\
\hline \multicolumn{3}{|c|}{ Age groups } \\
\hline Less than one year & 15864 & 7.9 \\
\hline $5-14$ & 41203 & 20.8 \\
\hline $15-44$ & 108509 & 54.7 \\
\hline$\geq 45$ & 32895 & 16.6 \\
\hline \multicolumn{3}{|c|}{ Gender } \\
\hline Male & 139284 & 70.2 \\
\hline Female & 59187 & 29.8 \\
\hline \multicolumn{3}{|c|}{ Occupation } \\
\hline Employed & 54915 & 27.7 \\
\hline Unemployed & 121502 & 61.2 \\
\hline Others & 22054 & 11.1 \\
\hline \multicolumn{3}{|c|}{ Marital status } \\
\hline Single & 37889 & 19.1 \\
\hline Married & 129042 & 65.0 \\
\hline Divorced, widowed & 31540 & 15.9 \\
\hline \multicolumn{3}{|c|}{ Types of vehicles } \\
\hline Motorcycle & 51025 & 25.7 \\
\hline Minibus & 31987 & 16.1 \\
\hline Car & 65187 & 32.9 \\
\hline Lorry & 30443 & 15.3 \\
\hline Pedestrian & 19829 & 10.0 \\
\hline
\end{tabular}

Table 2: Type of injuries.

\begin{tabular}{|c|c|c|}
\hline Types & Frequency & Percent \\
\hline Traumatic brain injuries & 21216 & 10.7 \\
\hline Fractures & 44361 & 22.4 \\
\hline Soft tissue injuries & 17985 & 9.1 \\
\hline Burnt chest injuries & 20362 & 10.2 \\
\hline Burnt abdominal injuries & 31520 & 15.9 \\
\hline Burns & 19251 & 9.7 \\
\hline Spinal injuries & 34520 & 17.4 \\
\hline Crush injuries & 9256 & 4.7 \\
\hline Total & 198471 & 100 \\
\hline
\end{tabular}

Table 3: Distribution of cases according to Abbreviated Injury Severity Scale (AIS).

\begin{tabular}{|c|c|c|}
\hline Abbreviated Injury Severity Scale & Frequency & Percent \\
\hline AIS1/ Minor & 23098 & 11.6 \\
\hline AIS2/Moderate & 31980 & 16.2 \\
\hline AIS3/ Serious but not life threatening & 65174 & 32.8 \\
\hline AIS4/Severe, life threatening & 21005 & 10.6 \\
\hline AIS5/Critical, survival uncertain & 44278 & 22.3 \\
\hline AIS6/Virtually un survivable & 12936 & 6.5 \\
\hline Total & 198471 & 100 \\
\hline
\end{tabular}

Table 4: Distribution of cases according to outcomes of RTA.

\begin{tabular}{|c|c|c|}
\hline Outcomes & Frequency & Percent \\
\hline Recovery & 65124 & 32.8 \\
\hline Absconded & 11096 & 5.6 \\
\hline Transferred to other hospital or unit & 44032 & 22.2 \\
\hline Died & 78219 & 39.4 \\
\hline Total & 198471 & 100 \\
\hline
\end{tabular}

Table 5: Survival time of Fatal Vehicular Accidents.

\begin{tabular}{|c|c|c|}
\hline Time of hospitalization & Frequency & Percent \\
\hline Instant death & 24158 & 30.9 \\
\hline Later death & 54061 & 69.1 \\
\hline Total & 78219 & 100 \\
\hline
\end{tabular}

Table 6: Period of hospitalization until death.

\begin{tabular}{|c|c|c|}
\hline Period of hospitalization & Frequency & Percent \\
\hline 0-24 hours & 17035 & 21.8 \\
\hline 1-10 days & 26474 & 33.8 \\
\hline 11-20 days & 14398 & 18.4 \\
\hline Over 21 days & 20312 & 26.0 \\
\hline Total & 78219 & 100 \\
\hline
\end{tabular}




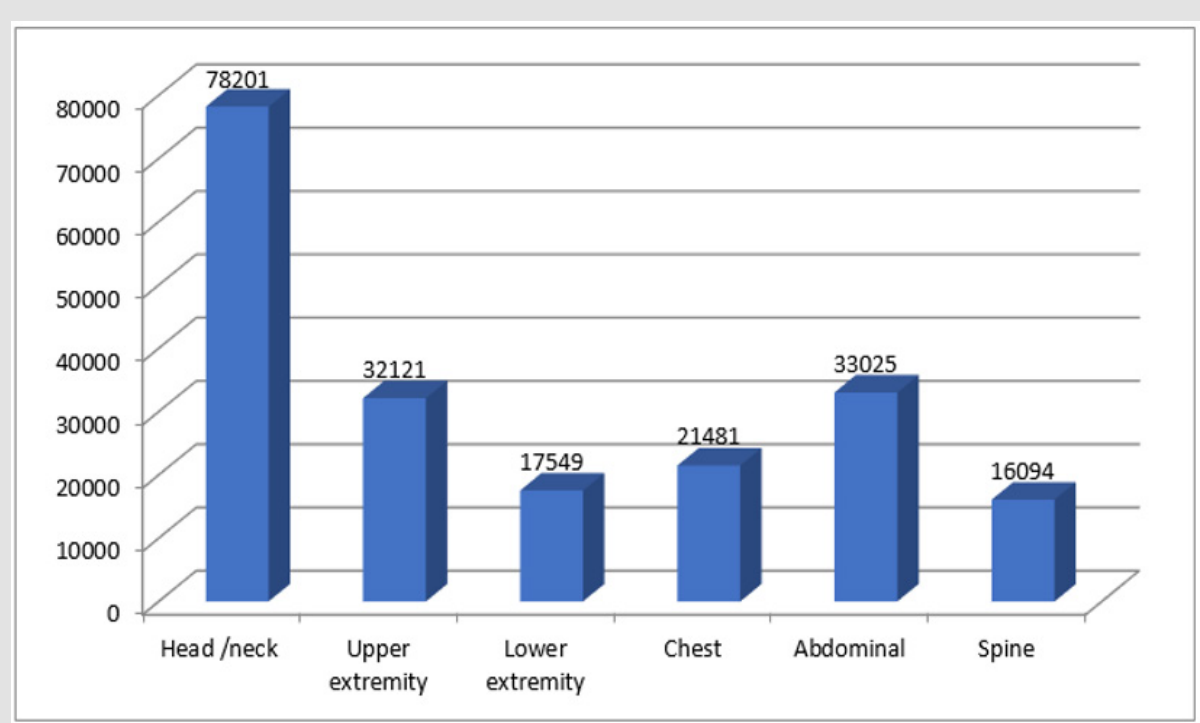

Figure 1: Distribution of RTA by body rejoins.

\section{Discussion}

This study aimed to identify the epidemiological, characteristics and outcomes of Road Traffic accident among patients in emergency unit during the study period. The most common age group affected in this study was 15 to 44 years old (54.7\%) and is agreement with other studies from other countries [23-25]. The ages in this category are the most active and energetic and the most of them are car users and, therefore it's represented the largest number of injuries and deaths resulting from accidents and, this has an impact on the economic, social and psychological level as well. Preventive measures are important to this category and, thus reduce the risks of exposure to severe danger that has an impact on the body. The result of accident is either disability or loss of life. Also, adolescents and young adults have different behavior when driving cars, including drinking, speeding, neglecting seat belts, risking driving at night, and racing against young people as a form of betting. Recent studies conducted in some countries indicate that young drivers between the ages of 18 and 27 years are more likely to be killed compared with other age groups, as well as lack of experience and risk are two factors associated with the occurrence of collision accidents among adolescents.

In our study, we found that the majority $70.2 \%$ of those exposed to accidents are males, and this is due to the predominance of men. As some of them become more aggressive in the street, as well as the dominance of men over the drivers of transport vehicles, because most of them spend their time outside the home and similar higher incidence of traffic accidents among males has been found by many other researchers [26-27]. In this study we found that the majority of victims of RTA $61.2 \%$ were unemployed and this finding in line with other finding done it in Nepal by Karkee [7], the author found that the majority of studied samples are unemployed. Most men prefer self-employment, especially in developing countries that suffer from unemployment and lack of job opportunities for their citizens. The higher percentage of victims $65 \%$ were married and compared with other results has done it in Iran by Hamzeh [4], Africa by Sango [9], Nigeria by Labinjo [13], they reported the majority of victims are married. Car accident represented the majority of victims of road traffic accidents (32.9\%), the same has been reported by Downing [28], but Kraus, et al. [29], found in San Diego that $62 \%$ of head injuries were to occupants of vehicles.

The higher percentage of car accident in this study may be attributed to failure of directing and controlling traffic. The type of road is also one of the risk factors, especially on external roads, where there are scarce paths, sidewalks and traffic lights, as well as lighting, as it poses the greatest danger and causes a high risk of death, especially at night, in addition to weather factors such as fog and rain, which cause poor visibility and this leads to the accident [30-31]. Previous studies indicate that drivers acquire many dangerous and harmful driving habits, especially in developing countries, and fail to comply with traffic rules. In some countries, the seat belt is ignored for the driver of the vehicle and other protective equipment such as the helmet for motorcyclists [32-33]. On the other hand the most commonly injury in similar studies was to the head (69.63\%) followed by chest (33.62\%) [34]. Out of 198471 cases, there is 44361 (22.4\%) had a fatal skull fracture. Similar findings were seen in few other studies. Most commonly found a spinal injury (17.4\%) which is consistent with the findings by other researchers [35-36]. 
Pre-hospital mortality was found to be in 24158 cases (30.9\%). The rest (69.1\%) was taken to hospital where later they succumbed to their injuries. This is nearly consistent with the study conducted in Iran with higher cases of pre-hospital mortality [37]. The present study observed that the most frequent lesions were in the head / neck (39.4\%) followed by abdominal injuries (16.6\%) and in upper extremity (16.2\%) and this finding in line with other findings in Thailand [1], Italy [30], Nepal [23], United Arab Emirate [33], they reported the head and neck the major lesions by RTA.

\section{Conclusion and Policy Implication}

In addition to the fact that road traffic injuries pose a significant health risk leading to a high rate of morbidity, disability and death, they have a significant social and economic impact on the victim, his family, and the nation as a whole. This study shows that most deaths in traffic accidents, brought to hospital, occur either immediately or within 24 hours of injury which is very worrying and highlights the need to take urgent steps to provide care services to them as quickly as possible. It also shows in our study that head injuries remain the most common and serious type of trauma seen in our hospital's emergency department and that quality neurosurgical care is essential for these patients. There is an urgent need to highlight the risk factors, conditions and chain to events that lead to accidents and it will be very useful for policy-making and health. In summary, it has been shown in this study that males, of younger ages, pose a higher risk, mortality and morbidity. Our findings may be useful for forensic experts, clinicians, and mechanical engineers looking for new vehicle occupant safety devices.

Deaths, injuries and disability after traffic accidents place a significant financial burden on the budgets of developing countries like ours. This problem must be resolved as soon as possible before causing more deaths in light of studies on the causes and prevention of traffic accidents and the support of international organizations.

\section{Recommendation}

To avoid traffic accidents, you must know the traffic rules and remind these rules of the media and social media in order to reinforce these rules, in addition to subjecting drivers to training, courses and conducting tests, including psychological testing, while reminding individuals of the benefits of using seat belts and helmets. In the future, it is possible to improve road networks and their quality, direct the weight of traffic to other means of transport outside the road, produce smarter, more durable, and more reliable vehicles, create separate roads to cyclists and pedestrians, take necessary measures to reduce road speed, and implement more effective traffic controls, more severe penalties for breaking the rules, driving with alcohol, and causing fatal accidents are among the first actions to take.

\section{Conflict of Interest}

None.

\section{References}

1. Chadbunchachai W, Suphanchaimaj W, Settasatien A, Jinwong T (2012) Road traffic injuries in Thailand: current situation. J Med Assoc Thai 95(7): S274-281.

2. Lee JS, Kim YH, Yum JS, Jung SE, Chae CS, et al. (2016) Characteristics of patients injured in road traffic accidents according to the new injury severity score. Ann Rehabil Med 40: 288-293.

3. Qirjako G, Burazeri G, Hysa B, Roshi E (2008) Factors associated with fatal traffic accidents in Tirana, Albania: cross sectional study. Croat Med J 49: 734-740.

4. Hamzeh B, Najafi F, Karaminatin B, Ahmadijiouybari T, Salari A, et al. (2016) Epidemiology of traffic crash mortality in west of Iran in a 9 year period. Chin J Traumatol 19: 70-74.

5. Der EM, Naporo S, Damnyag JB, Akosa AB (2016) Road traffic related deaths in Accra Ghana: A 10 year retrospective autopsy study at the Korle-Bu teaching hospital, Accra (2004-2013). J Forensic Pathol 1: 1-7.

6. Emara AM, Greiw AS, Hassan NA (2015) Pattern of road traffic injuries in patients admitted to AI-jlaa hospital, Benghazi, Libya. Tanta Med J 43: $39-45$.

7. Karkee R, Lee AH (2016) Epidemiology of road traffic injuries in Nepal, 2001-2013: systematic review and secondary data analysis. Br Med J Open 6: e010757.

8. Naci H, Chisholm D, Baker TD (2009) Distribution of road traffic deaths by road user group: a global comparison. Injury Prev 15: 55-59.

9. Sango AH, Testa J, Meda N, Contrand B, Traore MS, et al. (2016) Mortality and morbidity of urban road traffic crashes in Africa: capture-recapture estimates in Bamako, Mali, 2012. Public Lib Sci 12:1-8.

10. Chalya LP, Mabula JB, Dass RM, Mbelenge N, Ngayomela IH, et al. (2012) Injury characteristics and outcome of road traffic crash victims at Bugando Medical Centre in Northwestern Tanzania. J Trauma Manag Outcomes 6: 1-8.

11. Saidi H, Mutiso BK, Ogengo J (2014) Mortality after road traffic crashes in a system with limited trauma data capability. J Trauma Manag Outcomes 8: $2-6$

12. García-Altés A, Suelves JM, Barbería E (2013) Cost savings associated with 10 years of road safety policies in Catalonia, Spain. Bull World Health Organ 91: 28-35

13. Labinjo M, Juillard C, Kobusingye OC, Hyder AA (2009) The burden of road traffic injuries in Nigeria: Results of a population-based survey. Inj Prev 15: 157-162.

14. Mohtasham-Amiri Z, Dastgiri S, Davoudi-Kiakalyeh A, Imani A, Mollarahimi K (2016) An Epidemiological Study of Road Traffic Accidents in Guilan Province, Northern Iran in 2012. Bull Emerg Trauma 4: $230-235$

15. Pathak SM, Jindal AK, Verma AK, Mahen A (2014) An epidemiological study of road traffic accident cases admitted in a tertiary care hospital. Med J Armed Forces India 70: 32-35.

16. Ohakwe J, Iwueze IS, Chikezie DC (2011) Analysis of road traffic accidents in Nigeria: A case study of Obinze/Nekede/Iheagwa Road in Imo State, Southeastern, Nigeria. Asian J App Sci 4: 166-175.

17. Boniface R, Museru L, Kiloloma O, Munthali V (2016) Factors associated with road traffic injuries in Tanzania. Pan Afr Med J 23: 46. 
18. Technology Saves Lives", www.nhtsa.gov, Retrieved 12-10-2019. Edited

19. (2016) World Health Organization. Road safety in the South-East Asia region 2015, New Delhi, India.

20. (2015) WHO. Road traffic injuries.

21. Nilsson G (1986) Slipping-accidents. Report no. 291. Linkoping, Sweden: Swedish Road and Traffic Research Institute (VTI).

22. Hitosugi M, Takatsu A (2000) Injury severity in motor vehicle occupants. Legal Medicine 2: 166-170.

23. Jha N, Agrawal CS (2004) Epidemiological Study of Road Traffic Accident Cases: A Study from Eastern Nepal. Regional Health Forum WHO SouthEast Asia Region 8: 15-22.

24. Sharma BR, Harish D, Sharma V, Vij K (2001) Road Traffic accidents-a demographic and topographic analysis. Med Sci Law 41: 266-274.

25. BL Meel (2007) Trends in fatal motor vehicle accidents in Transkei region of South Africa. Med Sci Law 47: 64-68.

26. Salgado MSL, Colombage SM (1998) Analysis of fatalities in road accidents. Forensic Sci Int 36: 91-96.

27. Henriksson EM, Ostrom M, Eriksson A (2001) Preventability of vehiclerelated fatalities. Accid Ann Prev 33: 467-475.

28. Downing AJ (1989) Driver training in Africa: the UN-ECA driving manual. Proceedings of the Second African Road Safety Congress. Oslo: Institute of Transport Economics (TOI) 12.

ISSN: 2574-1241

DOI: 10.26717/BJSTR.2021.38.006173

Ahmed A H A, Wisam A K. Biomed J Sci \& Tech Res

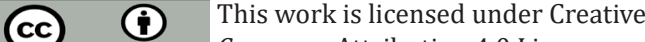

Submission Link: https://biomedres.us/submit-manuscript.php
29. Kraus JF, Black MA, Hessol N, Ley P, Rokaw W, et al. (1984) The incidence of acute brain injury and serious impairment in a defined population. Am J Epidemiol 119: 186-201.

30. Francesca Valent, Flavio Schiava, Cecilia Savonitto, Tolinda Gallo, Silvio Brusaferro, et al. (2002) Risk factors for fatal road traffic accidents in Udine, Italy. Accident Analysis and Prevention 34: 71-84.

31. Dupont E, Martensen H, Papadimitriou E, Yannis G (2010) Risk and protection factors in fatal accidents. Accid Anal Prev 42: 645-653.

32. Bener A, Abu-Zidan FM, Bensiali AK, Al-Mulla AAK, Jadaan KS (2003) Strategy to improve road safety in developing countries. Saudi Med J 24: 603-608.

33. Klenk G, Kovacks A (2003) Etiology and patterns of facial fractures in the United Arab Emirates. J Craniofac Surg 14: 78-84.

34. Arvind Kumar, Sanjeev Lalwani, Deepak Agrawal, Ravi Rautji, TD Dogra (2008) Fatal road traffic accidents and their relationship with head injuries: An epidemiological survey of five years. The Indian Journal of Neurotrauma 5: 63-67

35. Elesha SO, Daramola AO (2002) Fatal head injuries: the Lagos University Teaching Hospital experience (1993-1997). Niger Postgrad Med J 9: 3842.

36. Menon A, Pai VK, Rajeev A (2008) Pattern of fatal head injuries due to vehicular accidents in Mangalore. J Forensic Leg Med 15: 75-77.

37. Montazeri A (2004) Road-traffic-related mortality in Iran: a descriptive study. Public Health 118: 110-113.

$\begin{array}{ll}\text { BIOMEDICAL } & \text { Assets of Publishing with us } \\ \text { RESEARCHES } & \text { - Global archiving of articles } \\ \text { - Immediate, unrestricted online access }\end{array}$

